\title{
Amorphous polyamide/maleated styrene-ethylene- co-butylene-styrene nanocomposites: effects of clay loading and compatibilizer content on morphology and mechanical properties
}

\author{
Imanol González, José Ignacio Eguiazábal and Jon Nazábal
}

The effect of the organoclay content on the toughness of a rubbery modified amorphous polyamide (aPA)/organoclay-based nanocomposite was studied by changing the modifier (maleic anhydride) content. The dispersed rubber particle size decreased markedly with the addition of the modifier, indicating compatibilization of the nanocomposite. However, the particle size of the dispersed phase increased slightly with the organoclay content due to the interactions between the dissolved surfactant and the compatibilizer. Furthermore, we observed that the organoclay resided in the aPA matrix, and that its dispersion remained constant upon rubber addition. This resulted in materials with high stiffness and extremely large toughness values, as measured by both the standard impact strength and the essential work of the fracture method. Because the rubber content was kept constant, the inorganic part of the clay was proposed to be the main parameter that controls toughness.

Polymer Journal (2012) 44, 294-300; doi:10.1038/pj.2011.124; published online 30 November 2011

Keywords: amorphous polyamide; mechanical properties; melt processing; nanocomposites; organoclay; toughness

\section{INTRODUCTION}

Research in polymer nanocomposites (PNs) has shifted from the study of the best-performing organoclay for a given polymer ${ }^{1-6}$ to more complex systems where a third component, often a second polymer, is present. ${ }^{7,8}$ Consequently, this research area combines the versatility and advantages of both polymer blending and PNs. When properly dispersed, organically modified clays such as montmorillonite (OMMT) lead to large surface-to-volume and aspect ratios, which translates into significant improvements in the mechanical and physical properties, among others. A notable exception to this behavior is the toughness, which usually decreases with the addition of organoclays. This is attributed to the mobility restrictions that clay nanolayers impose on the surrounding matrix chains, thus limiting their plastic deformation. To overcome this limitation, a good approach is to use rubber toughening. Indeed, this strategy has been widely used to increase the toughness of PNs.

Polyamides are engineering polymers with attractive thermal and mechanical properties. The toughening of semicrystalline polyamides $^{9-12}$ and of their corresponding $\mathrm{PNs}^{13-16}$ has been described in numerous papers because they are well known to be highly notch sensitive. The chemical nature of amorphous polyamides (aPAs) is different from that of semicrystalline polyamides. This changes their interactions with modified rubbers and, consequently, their toughness behavior. The toughening of many $\mathrm{aPAs}^{17-21}$ and several of their $\mathrm{PNs}^{22,23}$ has been accomplished. However, the toughening of some aPA-based PNs still remains unstudied, and the deformation mechanisms of toughened $a \mathrm{PA} \mathrm{PNs}^{23}$ are far from understood.

Selar PA 3426 is an aPA that exhibits superior transparency, good barrier properties to gases, water, solvents and essential oils, and exceptional high-temperature structural properties, which make it suitable for a number of packaging applications. ${ }^{24}$ The larger amount of amine end groups present in Selar, compared with other commercial aPAs such as Zytel 330, make it more reactive. ${ }^{25}$ In addition, Selar is able to form fairly exfoliated PNs with commercially available modified clays, ${ }^{26}$ but to the best of our knowledge, no work has been published concerning its toughness. This gives us the opportunity to (i) study whether toughening of the PNs based on this aPA is possible and to (ii) gain a fundamental understanding of the mechanical constraints that the organoclay may impose on the toughness.

In this study, the aPA was first melt mixed with different amounts of organoclay $(1-5 \%)$ to ensure exfoliation, and then the obtained PNs were melt mixed with $25 \%$ maleinized styrene/ethylene-butylene/ styrene (mSEBS) triblock copolymer. The high to medium mSEBS 
content used (25\% of the polymeric components) should favor toughening despite the presence of OMMT and should prevent a substantial decrease in stiffness. The clay loading is an important parameter to study, as it will determine the tough/brittle transition. The MAH content also strongly influences the structure and properties of the PNs and was changed from $2 \%$, which is the largest content available in commercial mSEBS, to $1 \%$. The structure of the PNs with different clay and MAH contents was characterized by dynamic mechanical analysis; their morphology was studied by scanning electron microscopy; their nanostructure was examined by $\mathrm{X}$-ray diffraction (XRD) and transmission electron microscopy (TEM); and their mechanical properties were studied through tensile and instrumentalized and non-instrumentalized Izod impact tests.

\section{EXPERIMENTAL PROCEDURE}

The aPA used in this study was Selar PA3426R (Dupont, Wilmington, DE, USA), and the SEBS triblock copolymers were unmaleated Kraton G 1652 and G 1901X MAH functionalized SEBS (Kraton Performance Polymers Inc., Houston, TX, USA). The filler was an OMMT (Nanomer, I.30TC, Nanocor, Hoffman Estates, IL, USA) organically modified with octadecylamine. The OMMT content in the aPA matrix varied from 0 to 5\%. SEBS and MAH functionalized SEBS (mSEBS) were mixed to obtain the desired MAH contents ( 1 and $2 \%$ in the mSEBS phase). The mSEBS content in the PNs was fixed at $25 \%$ of the polymeric components. The PNs were named according to their OMMT and MAH contents, that is, 3\%-1 indicates a 75/25-3 aPA/mSEBSOMMT PN with $1 \%$ MAH content.

The OMMT (dried at $80^{\circ} \mathrm{C}$ in an air oven for $4 \mathrm{~h}$ ) and the pure aPA (dried at $100^{\circ} \mathrm{C}$ in vacuo for $24 \mathrm{~h}$ ) were fed to a Collin ZK25 co-rotating twin-screw extruder-kneader (Collin, Ebersberg, Germany) (screw diameter of $25 \mathrm{~mm}$ and length-to-diameter ratio of 30/1). The barrel temperature was $240^{\circ} \mathrm{C}$, and the rotation speed was 200 r.p.m. Subsequently, the aPA-OMMT/mSEBS PNs and the aPA/mSEBS 75/25 blend that was used as a reference were extruded at a barrel temperature of $240{ }^{\circ} \mathrm{C}$ and at a rotation speed of 80 r.p.m. After extrusion, the extrudates were cooled in a water bath and pelletized. Subsequent injection molding was conducted in a Battenfeld BA-230E reciprocating screw injectionmolding machine (Battenfeld IMT, Meinerzhagen, Germany) to obtain tensile (ASTM D638, type IV, thickness $2.0 \mathrm{~mm}$ ) and impact (ASTM D256, thickness $3.1 \mathrm{~mm}$ ) specimens. The screw of the plasticization unit was a standard screw with a diameter of $18 \mathrm{~mm}$, length-to-diameter ratio of 17.8 and a compression ratio of 4. The melt temperature was $240{ }^{\circ} \mathrm{C}$, and the mold temperature was $13^{\circ} \mathrm{C}$. The injection speed and pressure were $13.5 \mathrm{~cm}^{3} \mathrm{~s}^{-1}$ and $1870 \mathrm{bar}$, respectively.

The melt viscosity of pure aPA, aPA-OMMT PNs with 1,3 and 5\% OMMT content, and aPA/octadecylamine surfactant with the same amount of surfactant that is present in each PN $(0.3,0.9$ and $1.5 \%$, respectively) was measured by capillary extrusion in a Göettfert Rheotester 1000 rheometer (Göettfert, Buchen, Germany). The measurements were performed at an apparent deformation rate ranging from 50 to $5000 \mathrm{~s}^{-1}$ and at a temperature of $240{ }^{\circ} \mathrm{C}$ using a flat entry capillary tungsten die with a diameter of $1 \mathrm{~mm}$ and length-todiameter ratio of 30 .

The dynamic mechanical tests of the neat aPA and the PNs were performed using a TA Instruments DMA Q800 (TA Instruments, Wilmington, DE, USA) that provided the plots of the loss tangent $(\tan \delta)$ against the temperature. The scans were conducted in single cantilever mode at a constant heating rate of $4{ }^{\circ} \mathrm{C} \mathrm{min}^{-1}$ and at a frequency of $1 \mathrm{~Hz}$, from $-130^{\circ} \mathrm{C}$ until roughly $180^{\circ} \mathrm{C}$.

$\mathrm{XRD}$ patterns were recorded in an X'pert X-ray diffractometer from PANalytical company (Almelo, Overijssel, the Netherlands) operating at $40 \mathrm{kV}$ and $40 \mathrm{~mA}$ and using a Ni-filtered $\mathrm{K}_{\alpha} \mathrm{Cu}$ radiation source. The TEM samples of aPA/OMMT were embedded in an epoxy resin and ultrathinsectioned at $100 \mathrm{~nm}$ using an ultramicrotome; meanwhile, the TEM samples of aPA-OMMT/mSEBS PNs were ultrathin-sectioned at $60-80 \mathrm{~nm}$ using a cryoultramicrotome. The micrographs were obtained in a Philips Tecnai 20 apparatus (Philips, Eindhoven, the Netherlands) at an accelerating voltage of $200 \mathrm{kV}$. After gold coating, the surfaces of the cryogenically fractured specimens were observed by scanning electron microscopy. A Hitachi S-2700 electron microscope (Hitachi, Tokyo, Japan) was used at an accelerating voltage of $15 \mathrm{kV}$. The cryogenically fractured surfaces were previously etched with toluene for $2 \mathrm{~h}$ to remove the mSEBS. The particle size of the rubber was measured in representative zones of the cryogenically fractured impact specimens. The weightaverage particle size, $\bar{d}_{w}$, was calculated from a minimum of 200 particles as:

$$
\bar{d}_{w}=\frac{\sum_{i} n_{i} d_{i}^{2}}{\sum_{i} n_{i} d_{i}},
$$

where $n_{i}$ is the number of particles with size $d_{i}$.

Tensile tests were performed on the specimens according to ASTM D638 type IV using an Instron 5569 machine (Instron, High Wycombe, UK) at a cross-head speed of $10 \mathrm{~mm} \mathrm{~min}^{-1}$ and at $23 \pm 2{ }^{\circ} \mathrm{C}$ and $50 \pm 5 \%$ relative humidity. The Young's modulus was determined with an extensometer at a cross-head speed of $1 \mathrm{~mm} \mathrm{~min}^{-1}$. The mechanical properties (yield stress $\left(\sigma_{\mathrm{y}}\right)$ and ductility, measured as the break strain $\left(\varepsilon_{\mathrm{b}}\right)$ ) were determined from the load-displacement curves. Izod impact tests were performed on notched specimens (ASTM D256) using a CEAST 6548/000 (CEAST, Pianezza, Italy) pendulum. The notches (depth of $2.54 \mathrm{~mm}$ and radius of $0.25 \mathrm{~mm}$ ) were machined after injection molding. A minimum of six tensile specimens and eight impact specimens were tested for each reported value.

Instrumented Izod impact tests were performed on notched specimens using a CEAST 6548/000 pendulum with a DAS 8000 (CEAST) data acquisition system. In the essential work of fracture (EWF) procedure, the total fracture energy ( $W_{\mathrm{f}}$, calculated from the area under the load-displacement curves) is the addition of the surface-related essential work $\left(W_{\mathrm{e}}\right)$ to the volume-related nonessential work $\left(W_{\mathrm{p}}\right) . W_{\mathrm{e}}$ is a measure of the energy needed to create a new surface, and $W_{\mathrm{p}}$ is a measure of the energy-absorbing process surrounding the fracture surface. Using the specific energies $\left(w_{\mathrm{f}}, w_{\mathrm{e}}\right.$ and $\left.w_{\mathrm{p}}\right)$ :

$$
w_{\mathrm{f}}=w_{\mathrm{e}}+w_{\mathrm{p}} \beta l,
$$

where $l$ is the ligament length and $\beta$ is the shape factor of the plastic zone. According to equation 2, the straight line obtained by plotting $w_{\mathrm{f}}$ (obtained from the impact test and the ligament area) versus $l$ for different ligament lengths provides $w_{\mathrm{p}} \beta$ (the slope) and $w_{\mathrm{e}}$ (the $y$ intercept).

\section{RESULTS AND DISCUSSION}

\section{Phase behavior}

The phase behavior of the PNs was characterized by dynamic mechanical analysis. The two tan $\delta$ peaks of the PNs were very similar to those of the binary aPA/mSEBS blend and appeared at the same temperature as those of the pure components. This result is in agreement with that previously reported for other polyamides with ${ }^{27,28}$ and without ${ }^{29}$ clay. Thus, the PNs contain two pure polymeric amorphous phases, and the presence of OMMT does not change the phase behavior of the blend matrix.

\section{Characterization of the nanostructure}

The nanostructure of the PNs was studied both by XRD and TEM. The XRD plots of the PN with 2\% MAH, the aPA-3\% OMMT reference PN and the OMMT are shown in Figure 1. The plots of the PNs with 1 and $2 \% \mathrm{MAH}$ are very similar, wherein the characteristic peak of OMMT at $2 \theta=3.40^{\circ}$ (ref. 30) is readily observed. This value corresponds to a basal spacing of $2.60 \mathrm{~nm}$. The lack of a diffraction peak in the XRD plots of the ternary PNs indicates the probable formation of an exfoliated nanostructure. Moreover, the plots of the PNs are very similar to that of the aPA-3\% OMMT, indicating that mSEBS did not influence the dispersion of the OMMT.

The nanostructure of the 3\%-2 PNs obtained by TEM is shown in Figure 2. As shown, the addition of mSEBS did not lead to any layer compaction because the degree of exfoliation of the clay in the PNs was almost complete, and was comparable with that of the pure aPA-3\%.

Furthermore, we observed that the clay layers (Figure 2) remained within the aPA matrix, and no preferential segregation of the clay to 


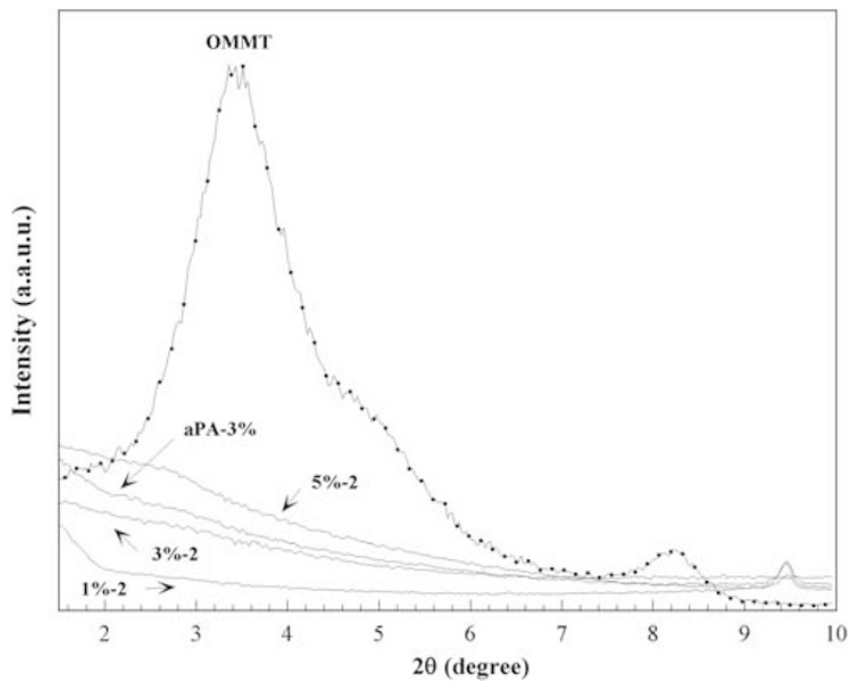

Figure 1 X-ray diffraction patterns for montmorillonite (OMMT), amorphous polyamide (aPA)-3\% OMMT, and 3\%-2 and 5\%-2 polymer nanocomposites.

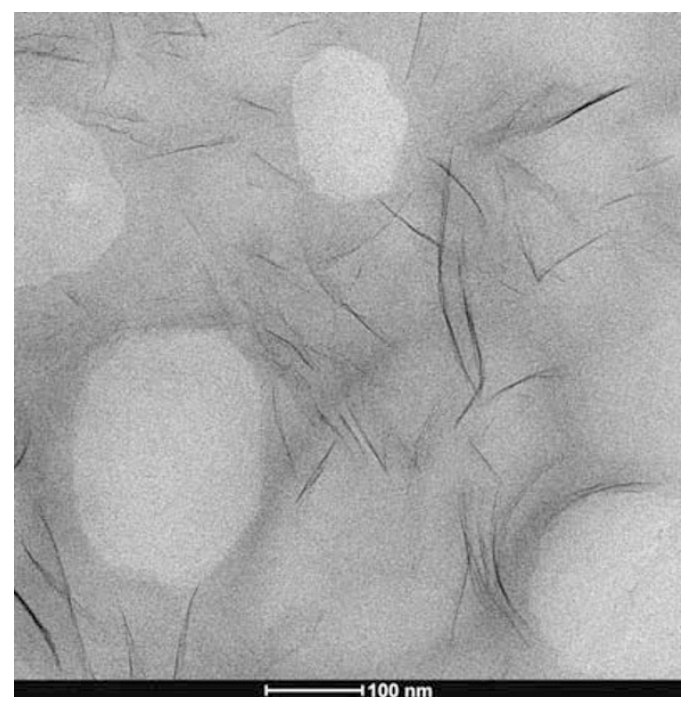

Figure 2 Transmission electron microscopy photomicrographs of the 3\%-2 polymer nanocomposite.

the interphase was seen. Consequently, the clay did not migrate to the rubber phase during the additional processing incurred by the addition of mSEBS, and therefore, the rubbery nature of the dispersed phase was fully preserved in the PNs.

\section{Morphology}

Figures $3 \mathrm{a}$ and $\mathrm{b}$ shows the morphology of the 0\%-1 (reference blend) and 3\%-1 PN, respectively. The dispersed particle sizes of these PNs and of the PNs with 2\% MAH are presented in Table 1. The particle size decreased with increasing MAH content, indicating additional compatibilization. The compatibilization is attributed to chemical interactions between the amine end groups of aPA and the MAH groups of mSEBS. ${ }^{10,31}$ This increase in compatibilization does not always occur, as evidenced by the $\mathrm{PBT} / \mathrm{maleinized} \mathrm{poly(ethylene}$ octene) blends modified with phenoxy, ${ }^{32}$ for which the particle size reaches a minimum at $\mathrm{MAH}$ contents above $0.63 \%$.
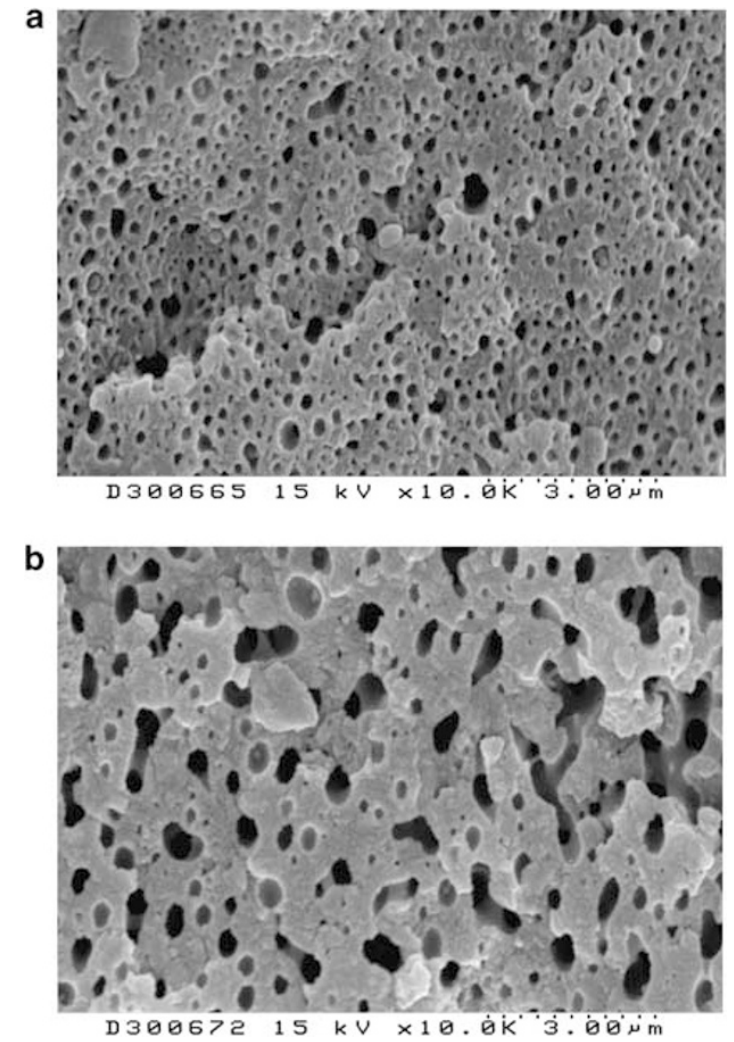

Figure 3 Cryofractured etched surfaces of the injection-molded impact specimens of (a) 0\%-1 (reference blend) and (b) 3\%-1 polymer nanocomposite.

Table 1 Dispersed particle size of the ternary PNs with 1 and $2 \%$ MAH contents versus the OMMT content

\begin{tabular}{lcc}
\hline & \multicolumn{2}{c}{ Particle diameter $(\mu \mathrm{m})$} \\
\cline { 2 - 3 } OMMT (\%) & Ternary PNs (MAH: 1\%) & Ternary PNs (MAH: 2\%) \\
\hline 0 & 0.27 & 0.09 \\
1 & 0.34 & 0.18 \\
2 & 0.49 & 0.24 \\
3 & 0.61 & 0.35 \\
4 & 0.88 & 0.49 \\
5 & 1.25 & 0.54 \\
\hline
\end{tabular}

Abbreviations: MAH, maleic anhydride; OMMT, montmorillonite; PN, polymer nanocomposite.

The morphology of the reference blend and that of the 1\%-1 PN are similar. However, at 5\% OMMT content there is a clear increase in particle size, and the morphology changes from sphere-like to wider cross-sections, suggesting coalescence.

The capillary number ${ }^{33,34}$ is the ratio of the viscous stress required to deform the particle in a simple shear flow to the interfacial tension that tends to keep the particle spherical and is defined as:

$$
C_{\mathrm{a}}=\frac{\eta_{\mathrm{m}} \dot{\gamma}}{\sigma / R}
$$

where $\eta_{\mathrm{m}}$ is the viscosity of the matrix, $\dot{\gamma}$ is the shear rate, $\sigma$ is the interfacial tension and $R$ is the particle radius. It is well known that $C_{\mathrm{a}}$ determines the particle size of a dispersed phase in a polymer blend; 


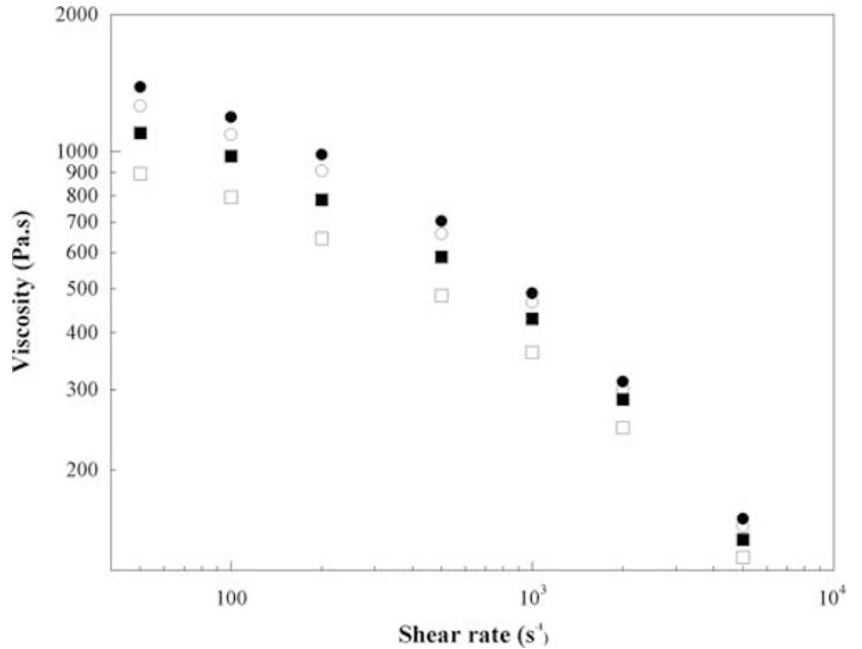

Figure 4 Apparent viscosity of the binary polymer nanocomposites with amorphous polyamide (aPA)- $1 \%(\mathrm{O}), \quad$ aPA-3\% (口), aPA-5\% ( $\square)$ montmorillonite and of the pure aPA $(\bullet)$ as a function of the shear rate at $240^{\circ} \mathrm{C}$.

Table 2 Matrix viscosity and particle size of the 75/25 blend with $2 \%$ MAH and added surfactant

\begin{tabular}{lcc}
\hline $\begin{array}{l}\text { Added surfactant } \\
\text { content (\%) }\end{array}$ & $\begin{array}{c}\text { Matrix viscosity } \\
\left(2000 \mathrm{~s}^{-1}\right)\end{array}$ & $\begin{array}{c}\text { Particle size } \\
(\mu \mathrm{m} ; \pm 0.05)\end{array}$ \\
\hline 0 & 312 & 0.09 \\
That of the 1\% OMMT & 272 & 0.19 \\
That of the 3\% OMMT & 241 & 0.31 \\
That of the 5\% OMMT & 205 & 0.50 \\
\hline
\end{tabular}

Abbreviations: MAH, maleic anhydride; OMMT, montmorillonite.

a particle breaks up at a critical $C_{\mathrm{a}}$ that depends on the type of flow (shear or elongational) and the viscosity ratio. We can rule out the clay as a possible source of the particle size increase because it acts as a barrier, preventing coalescence and therefore decreasing the particle size. Furthermore, the processing conditions, such as $\dot{\gamma}$, were the same for all OMMT contents, which suggests that either the viscosity of the matrix or the interfacial tension is responsible for this change in particle size.

The viscosity of the pure aPA modified with $0,1,3$ and 5\% OMMT was measured by capillary rheometry, and the results are shown in Figure 4. As shown, at higher shear rates (predominant in the extrusion process), the viscosity changed upon the addition of OMMT. However, the change was not large enough to justify the high increase in rubber particle size that was observed. ${ }^{35}$

The interfacial tension of the nanocomposites was not directly modified by the clay particles because they were not located at the interface. However, it has been observed ${ }^{27}$ that the free surfactant present in commercial organoclays, which arises from the excess of surfactant used in the ionic interchange reaction between the $\mathrm{Na}^{+}$ions and the octadecylamonium salt, may migrate to the matrix during melt mixing without altering the basal spacing of the OMMT. This surfactant can interact/react with the MAH groups of the rubber at the interface, shielding the desired compatibilization reaction with the amine end groups of the polyamide. This would decrease its compatibilizing efficiency and would lead to an increase in particle size. To

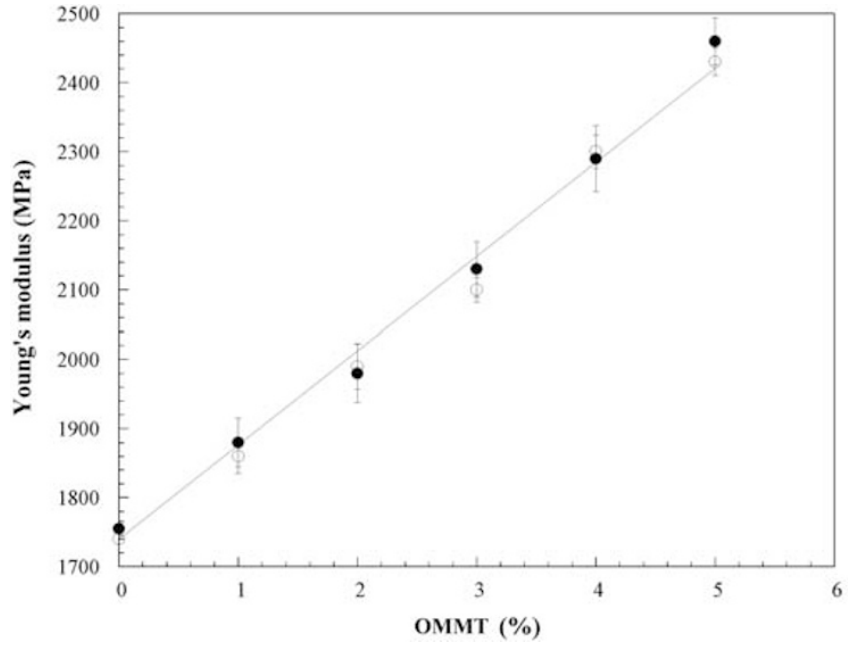

Figure 5 Young's modulus of the ternary polymer nanocomposites (PNs) at grafting levels of $1 \%(\bigcirc)$ and $2 \%(\bullet)$ versus the montmorillonite (OMMT) content.

test this possibility, the surfactant of the OMMT was mixed with the aPA. The effects of the pure surfactant addition on the matrix viscosity and on the dispersed particle size are summarized in Table 2. It is readily observed that the addition of surfactant decreased the viscosity of the pure aPA. However, this decrease was not large enough to significantly change the particle size. The increase in particle size (from 0.19 to 0.31 and $0.50 \mu \mathrm{m}$ ) was very close to that observed in the PNs shown in Table 1 (from 0.18 to 0.35 and $0.54 \mu \mathrm{m}$ ). This demonstrates that the increase in the dispersed particle size with the OMMT content is related to the surfactant and is probably due to interactions between the surfactant and the MAH substitution. The decrease in particle size associated with an increase in MAH from 1 to $2 \%$ agrees with this hypothesis.

\section{Mechanical properties}

The Young's modulus values of the PNs with both $1 \%$ (empty circles) and 2\% MAH (filled circles) are shown in Figure 5 as a function of the OMMT content. The corresponding plot of the yield stress showed a similar trend, although the absolute changes were less significant than those of the modulus, as expected. Figure 5 indicates that the modulus values for the $\mathrm{PNs}^{36}$ are independent of the MAH content. This result is attributed to the low interfacial adhesion needed for stress transmission through the interface when small strain properties such as the modulus of elasticity are measured.

Figure 5 also shows that the Young's modulus increased continuously with the OMMT content. The increase was approximately $40 \%$ of the original value in the PN with 5\% OMMT. This suggests that a large percentage of the modulus decrease caused by the presence of rubber (from $2750 \mathrm{MPa}$ in the aPA to $1740 \mathrm{MPa}$ in the $75 / 25$ blend) is offset by the addition of OMMT (2400 MPa in the 5\% PN). The relative modulus increases are very similar to those observed in the PNs based on the pure $\mathrm{aPA}^{26}$ at the same conditions. This indicates a similar dispersion level of the OMMT in both the aPA and the reference aPA/mSEBS blend, and shows that the presence of mSEBS does not hinder exfoliation.

The elongation at break values for the PNs are shown in Figure 6 as a function of the OMMT content. The elongation at the break essentially remained constant up to 3\% OMMT, but decreased drastically at higher OMMT contents. The decrease in ductility, 


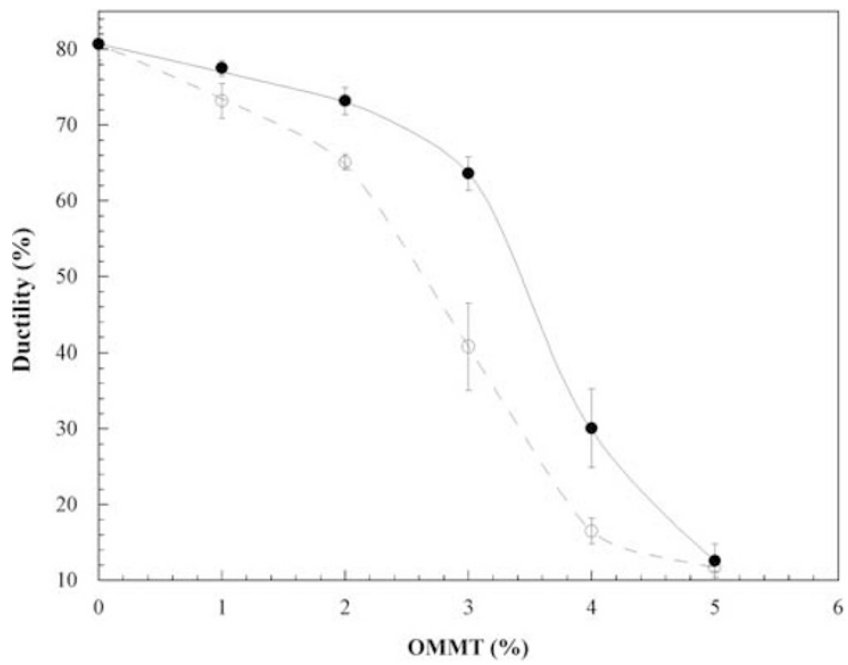

Figure 6 Ductility of the ternary polymer nanocomposites versus the montmorillonite (OMMT) content. Symbols as explained in Figure 5.

however, is not as large as shown in Figure 6 because all the PNs yielded, and consequently, they were ductile. Thus, the yielding ability of the blends was preserved; it was their ability to be cold-drawn that decreased. The fine size of the dispersed phase probably preserved the ductility.

Figure 6 also shows that the elongation at break of the PNs increased slightly with the compatibilizer (MAH) content. The elongation at break of multiphase systems can be affected by changes in both the morphology (dispersed particle size) and the interfacial adhesion. ${ }^{37}$ The increase of the compatibilizer content from 1 to $2 \%$ in this work translated to both a notable decrease in particle size, due to the decrease in interfacial tension, and an increase in the interfacial adhesion due to the improvement of stress transmission around the interface caused by the presence of the copolymer. ${ }^{37}$ Both of these effects are responsible for the observed increase in the elongation at break.

Decreases in ductility with increasing OMMT content have often been reported ${ }^{23,38-40}$ in polymer/clay PNs and have been attributed to both the presence of large clay agglomerates and to an increase in the stiffness of the matrix. In these PNs, the matrix stiffness increased but the amount of clay agglomerates remained constant with increasing OMMT content. Thus, the decrease in ductility is attributed to restrictions in the mobility of the matrix chains imposed by the clay layers, which promote rapid fractures.

The notched impact strength of the PNs is shown in Figure 7 as a function of the OMMT content. The negligible impact strength of the pure aPA $\left(13 \mathrm{~J} \mathrm{~m}^{-1}\right)$ contrasts with the very high toughness attained after adding $25 \% \mathrm{mSEBS}\left(820 \mathrm{~J} \mathrm{~m}^{-1}\right)$. This represents an increase greater than 60 -fold, which occurs regardless of the MAH content in the PNs. In addition, materials such as the $3-2 \%$ PN show considerable stiffness (modulus of $2150 \mathrm{MPa}$, compared with $2750 \mathrm{MPa}$ in the case of the aPA) together with a very tough nature $\left(380 \mathrm{~J} \mathrm{~m}^{-1}\right.$ in comparison with the negligible toughness of the aPA). Moreover, the impact strength of the PNs did not greatly depend on the MAH content (therefore, on the rubber morphology). Because the rubber particle size depended on the MAH content (Table 1), the impact strength remained in the $0.05-1 \mu \mathrm{m}$ particle size range characteristic of the PNs used in this study.

As seen in Figure 7, the presence of OMMT reduced the impact strength of the PNs, which could be due to either the inorganic or the

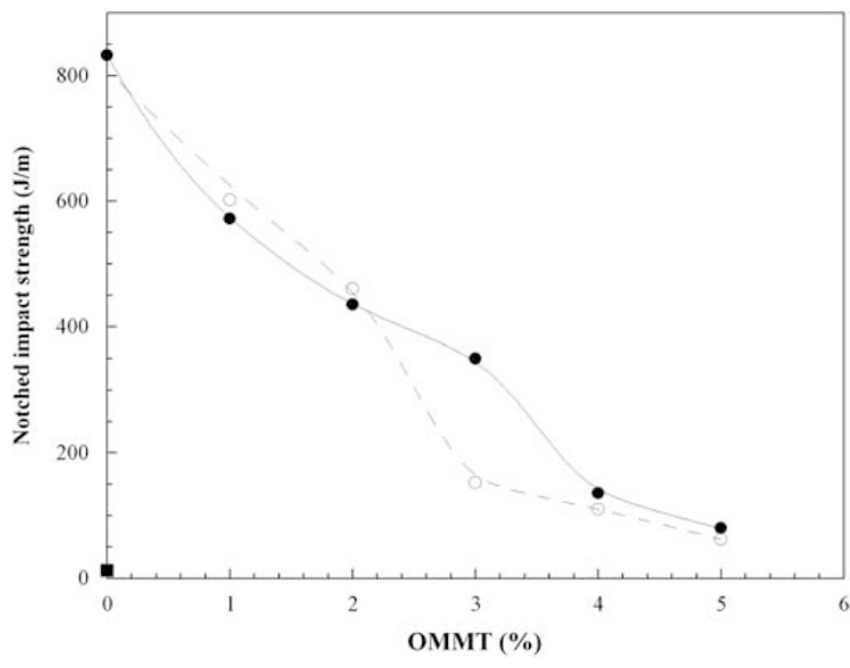

Figure 7 Notched impact strength of the ternary polymer nanocomposites at grafting levels of $1 \%(\bigcirc), 2 \%(\bullet)$ and the pure amorphous polyamide ( $\mathbf{\square})$ as reference versus the montmorillonite (OMMT) content.

Table 3 Notched impact strength of the 75/25 blend with 2\% MAH and added surfactant

\begin{tabular}{lcc}
\hline $\begin{array}{l}\text { Added surfactant } \\
\text { content (\%) }\end{array}$ & $\begin{array}{c}\text { Notched impact strength } \\
\text { of the blends with added } \\
\text { surfactant }\left(\mathrm{J} \mathrm{m}^{-1}\right)\end{array}$ & $\begin{array}{c}\text { Notched impact } \\
\text { strength of the } \\
P N \mathrm{~N}\left(\mathrm{~J} \mathrm{~m}^{-1}\right)\end{array}$ \\
\hline 0 & 833 & - \\
That of the 1\% OMMT & 840 & 572 \\
That of the 3\% OMMT & 824 & 350 \\
That of the 5\% OMMT & 836 & 80 \\
\hline
\end{tabular}

Abbreviations: MAH, maleic anhydride; OMMT, montmorillonite; PN, polymer nanocomposite The impact strength of the corresponding PNs is also recorded as a reference.

organic part (surfactant) of the OMMT. The inorganic part may lead to mechanical constraints, which can reduce the matrix-yielding extension. ${ }^{23}$ The surfactant can modify the impact strength either by inducing an increase in particle size (see Morphology section) or by changing the interface conditions. The fabrication of PNs without a surfactant would not help to distinguish the contributions of the inorganic and organic parts of the OMMT, because the degree of dispersion would be different in the PNs. However, as described in the Morphology section, a mixture that is analogous to the PN can be made by adding a surfactant to the aPA/mSEBS blends in the same amount that is present in the PNs. The impact strength of the blends with surfactant is shown in Table 3, along with the corresponding values of the PNs.

The first column in Table 3 shows that changing the amount of surfactant present in the blends (change of interphase conditions) does not change the impact strength. In addition, in the second column of Table 2 we observe that the particle size of the blends (the same particle size as that of the PNs) changed with the surfactant content, but the change had no effect on the impact strength (Table 3, first column). Therefore, neither the surfactant content nor the particle size influenced the impact strength. However, a comparison of the first and second columns in Table 3 indicates that the presence of inorganic clay influences the impact strength, and consequently, the 


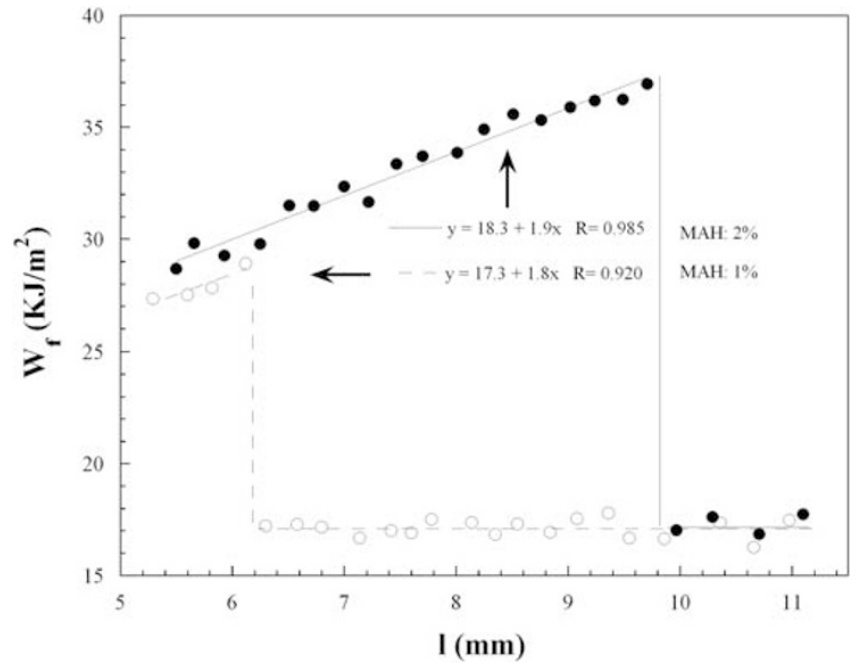

Figure 8 Specific fracture energy versus ligament length for 3\%-1 $(O)$ and $3 \%-2(\bullet)$ polymer nanocomposites. MAH, maleic anhydride.

inorganic part of the OMMT is the main parameter controlling the impact values (toughness) in the PNs.

Figure 7 also shows that the brittle/tough transition depends on the MAH content (and, consequently, on the morphology) because it occurs between 2 and 3\% OMMT in the case of the 1\% MAH PNs, and between 3 and $4 \%$ for the 2\% MAH PNs. This seems to indicate that with increasing compatibilizer content (decreasing particle size), the brittle/tough transition shifted to higher OMMT contents and that the PNs are tougher over a wider range of filler contents. Traditional impact tests have serious limitations (primarily related to the notch geometry) that drastically reduce the significance of the results, because the test does not provide any value of toughness that might be deemed a fundamental parameter of the material. To gain insight into both of the parameters on which toughness depends and into the position of the brittle/tough transition, the EWF methodology, which is seldom used in plastics, was used to calculate the specific fracture energy of the 3\%-1 and 3\%-2 PNs as a function of ligament length (Figure 8). The shape of the load-displacement curves of both PNs was geometrically similar irrespective of the ligament length, satisfying the requirements of the EWF methodology and validating the values of the specific fracture energy that were obtained.

A change in particle size occurred between 3\%-1 (white symbols) and 3\%-2 (black symbols) due to the increase in the compatibilizer content, but the particle size remained constant regardless of the ligament length. As seen in Figure 8, both the essential ( $y$ intercept) and non-essential (slope of the line in the tough zone) work of the fracture parameters and the impact toughness were independent of the MAH content, and consequently, independent of the particle size within the experimental range that was studied. However, the brittle/ tough transition occurred at unmistakably different ligament lengths for the 1 and 2\% MAH PNs (6.2 and $9.8 \mathrm{~nm}$, respectively).

\section{CONCLUSIONS}

The exfoliation level of the OMMT in the PNs was comparable with that of the pure aPA matrix. Moreover, the clay layers remained in the aPA matrix, reinforcing the matrix and preserving the rubbery nature of the dispersed phase.

The dispersed particle size clearly decreased with MAH content, which provides evidence of compatibilization. The addition of a small amount of OMMT (1\%) did not significantly change the morphology, but a higher OMMT content (5\%) led to coarser morphologies. After discarding the possibility of a physical effect associated with the difference in the viscosity of the PNs, we proposed that the increase in particle size was caused by interactions between the dissolved surfactant and the compatibilizer.

The decrease in the modulus caused by the addition of rubber was largely offset by the presence of OMMT. This allowed us to obtain ductile PNs with both sufficient stiffness and a very large impact strength.

Both the impact strength and, more importantly, the toughness values obtained from the EWF procedure showed that using 1\% MAH is enough to obtain sufficiently high toughness in the PNs. The change in particle size that was observed between the PNs with 1 and $2 \%$ $\mathrm{MAH}$ affected the brittle/tough transition, but did not affect either the impact strength values or the EWF parameters.

\section{ACKNOWLEDGEMENTS}

The financial support of the Spanish Ministerio de Ciencia e Innovación (project MAT2010-16171) and of the Basque Government (project IT-234-07) is gratefully acknowledged. The technical support of the Polymer Characterization Service of the University of Basque Country for the TEM and XRD analyses are gratefully acknowledged.

1 Lim, S. H., Dasari, A., Wang, G. T., Yu, Z. Z., Mai, Y. W., Yuan, Q., Liu, S. \& Yong, M. S. Impact fracture behaviour of nylon 6-based ternary nanocomposites. Compos. Eng. 41B, 67-75 (2010).

2 Ali, Z., Le, H.- H., Ilisch, S., Thurn-Albrecht, T. \& Radusch, H.- J. Morphologydevelopment and compatibilization effect in nanoclay filled rubber blends. Polymer 51, 4580-4588 (2010).

3 Mirzadeh, A., Lafleur, P. G., Kamal, M. R. \& Dubois, C. The effect of compatibilizer on the co-continuity and nanoclay dispersion level of TPE nanocomposites based on PP/EPDM. Polym. Eng. Sci. 50, 2131-2142 (2010).

4 Borse, N. K. \& Kamal, M. R. Melt processing effects on the structure and mechanical properties of PA-6/clay nanocomposites. Polym. Eng. Sci. 46, 1094-1103 (2006).

5 Uribe-Calderon, J. \& Kamal, M. R. Evaluation of various surfactants and compatibilizers for preparation of PS/clay nanocomposites by melt compounding. J. Polym. Eng. 30, 377-411 (2010).

6 Motovilin, M., Denchev, Z. \& Dencheva, N. On the structure-properties relationship in montmorillonite-filled polyamide 6 nanocomposites. J. Appl. Polym. Sci. 120, 3304-3315 (2011).

7 Mehrabzadeh, M. \& Kamal, M. R. Melt processing of PA-66/clay, HDPE/clay and HDPE/ PA-66/clay nanocomposites. Polym. Eng. Sci. 44, 1152-1161 (2004).

8 As'habim, L., Jafarim, S. H., Khonakdar, H. A. \& Baghaei, B. Morphological, rheological and thermal studies in melt processed compatibilized PA6/ABS/clay nanocomposites. J. Polym. Res. 18, 197-205 (2010).

9 Oshinski, A. J., Keskkula, H. \& Paul, D. R. Rubber toughening of polyamides with functionalized block copolymers: 2. Nylon-6,6. Polymer 33, 284-293 (1992).

10 Oshinski, A. J., Keskkula, H. \& Paul, D. R. Rubber toughening of polyamides with functionalized block copolymers: 1. Nylon-6. Polymer 33, 268-283 (1992).

11 Majumdar, B., Keskkula, H. \& Paul, D. R. Reactive compatibilization of Nylon-6/Abs blends with a Functionalized imidized acrylic polymer-mechanical-properties and morphology generation. Abst. Pap. Amer. Chem. Soc. 206, 9-11 (1993).

12 Borggreve, R. J. M., Gaymans, R. J., Schuijer, J. \& Ingen Housz, J. F. Brittle-tough transition in nylon-rubber blends: effect of rubber concentration and particle size. Polymer 28, 1489-1496 (1987).

13 González, I., Eguiazabal, J. I. \& Nazabal, J. Compatibilization level effects on the structure and mechanical properties of rubber-modified polyamide-6/clay nanocomposites. J. Polym. Sci. Polym. Phys. 43, 3611-3620 (2005).

14 Ahn, Y. C. \& Paul, D. R. Rubber toughening of nylon 6 nanocomposites. Polymer 47 2830-2838 (2006)

15 Dasari, A., Yu, Z. Z. \& Mai, Y. W. Effect of blending sequence on microstructure of ternary nanocomposites. Polymer 46, 5986-5991 (2005).

16 Dermanaki, R. \& Ramazani, A. Melt preparation and investigation of properties of toughened Polyamide 66 with SEBS-g-MA and their nanocomposites. Mat. Des. 29, 105-111 (2007).

17 Huang, J. J., Keskkula, H. \& Paul, D. R. Rubber toughening of an amorphous polyamide by functionalized SEBS copolymers: morphology and Izod impact behavior. Polymer 45, 4203-4215 (2004).

18 Huang, J. J., Keskkula, H. \& Paul, D. R. Elastomer particle morphology in ternary blends of maleated and non-maleated ethylene-based elastomers with polyamides: role of elastomer phase miscibility. Polymer 47, 624-638 (2006). 
19 Huang, J. \& Paul, D. R. Comparison of fracture behavior of nylon 6 versus an amorphous polyamide toughened with maleated poly(ethylene-1-octene) elastomers. Polymer 47, 3505-3519 (2006).

20 Huang, J. J., Keskkula, H. \& Paul, D. R. Comparison of the toughening behavior of nylon 6 versus an amorphous polyamide using various maleated elastomers. Polymer 47, 639-651 (2006).

21 Gonzalez, I., Eguiazabal, J. I. \& Nazabal, J. Toughening and brittle-tough transition in blends of an amorphous polyamide with a modified styrene/ ethylene-butylene/styrene triblock copolymer. Polym. Eng. Sci. 49, 1350-1356 (2009).

22 Yoo, Y., Tiwari, R. R., Yoo, Y. T. \& Paul, D. R. Effect of organoclay structure and mixing protocol on the toughening of amorphous polyamide/elastomer blends. Polymer 51, 4907-4915 (2010).

23 Yoo, Y., Cui, L., Yoon, P. J. \& Paul, D. R. Morphology and mechanical properties of rubber toughened amorphous polyamide/MMT nanocomposites. Macromolecules 43, 615-624 (2010).

24 Dupont Selar Data Sheets. http://www2.dupont.com/Selar/en_US/assets/downloads/ selar_pa_3426.pdf.

$25 \mathrm{Ji}$, S., Hoye, T. R. \& Macosko, C. W. Primary amine (-NH2) quantification in polymers: functionality by $19 \mathrm{~F}$ NMR spectroscopy. Macromolecules 38, 4679 (2005).

26 Goitisolo, I., Eguiazabal, J. I. \& Nazabal, J. Structure and properties of an amorphous polyamide based nanocomposite. Polym. Adv. Tech. 20, 1060-1067 (2009).

27 Gonzalez, I., Eguiazabal, J. I. \& Nazabal, J. Rubber-toughened polyamide 6/clay nanocomposites. Compos. Sci. Tech. 66, 1833-1843 (2006).

28 Gonzalez, I., Eguiazabal, J. I. \& Nazabal, J. Nanocomposites based on a polyamide 6/maleated styrene-butylene-co-ethylene-styrene blend: effects of clay loading on morphology and mechanical properties. Eur. Polym. J. 42, 2905-2913 (2006).

29 Wu, C. J., Kuo, J. F., Chen, C. Y. \& Woo, E. Effects of reactive functional-groups in the compatibilizer on mechanical-properties of compatibilized blends. J. Appl. Polym. Sci. 52, 1695-1706 (1994).
30 Chang, J. H., Park, K. M. \& Cho, D. Preparation and characterization of polyimide nanocomposites with different organo-montmorillonites. Polym. Eng. Sci. 41, 15141520 (2001).

31 Nishitani, Y., Yamada, Y., Ishii, C., Sekiguchi, I. \& Kitano, T. Effects of addition of functionalized SEBS on rheological, mechanical, and tribological properties of polyamide 6 nanocomposites. Polym. Eng. Sci. 50, 100-112 (2010).

32 Arostegui, A. \& Nazabal, J. Stiffer and super-tough poly(butylene terephthalate) based blends by modification with phenoxy and maleated poly(ethylene-octene) copolymers. Polymer 44, 239-249 (2003).

33 Zhang, B. Q., Ding, Y. F., Chen, P., Liu, C. Y., Zhang, J., He, J. S. \& Hu, G. H. Fibrillation of thermotropic liquid crystalline polymer enhanced by nano-clay in nylon- 6 matrix. Polymer 46, 5385-5395 (2005).

34 Shariatpanahi, H., Nazokdast, H. \& Hemmati, M. Relationship between interfacial tension and dispersed-phase particle size in polymer blends. II. PP/PA6. J. Appl. Polym. Sci. 88, 54-63 (2003).

35 D'Orazio, L., Mancarella, C., Martuscelli, E., Sticotti, G. \& Massari, B. Melt rheology, phase structure and impact properties of injection-moulded samples of isotactic polypropylene/ethylene-propylene copolymer (iPP/EPR) blends: influence of molecular structure of EPR copolymers. Polymer 34, 3671-3681 (1993).

36 Gonzalez, I., Eguiazabal, J. I. \& Nazabal, J. Compatibilization level effects on the structure and mechanical properties of rubber-modified polyamide-6/clay nanocomposites. J. Polym. Sci. Polym. Phys. 43, 3611-3620 (2005).

37 Kolarik, J. \& Lednicky, F. Blends of polycarbonate with poly(styrene-co-acrylonitrile): miscibility, interfacial adhesion, tensile properties, and phase structure. Polym. Net. Blend. 3, 147-154 (1993).

38 Cho, J. W. \& Paul, D. R. Nylon 6 nanocomposites by melt compounding. Polymer $\mathbf{4 2 ,}$ 1083-1094 (2001).

39 Fornes, T. D., Hunter, D. L. \& Paul, D. R. Nylon-6 nanocomposites from alkylammoniummodified clay: the role of alkyl tails on exfoliation. Macromolecules 37, 1793-1798 (2004).

40 Xie, S. B., Zhang, S. M., Zhao, B., Qin, H. L., Wang, F. S. \& Yang, M. S. Tensile fracture morphologies of nylon-6/montmorillonite nanocomposites. Polym. Inter. 54, 1673-1680 (2005). 